\title{
Does COVID-I 9 antibody screening in the staff of dialysis centers enhance patient safety?
}

\section{Letter to editor}

Caring for patients undergoing maintenance hemodialysis $(\mathrm{MH})$ in times of the COVID-19 pandemic leads to several problems. Clinically, the initial symptoms of such an infection are rather atypical in dialysis patients and mortality is high in the case of an overt infection. Wu et al., ${ }^{1}$ performed a retrospective study in Wuhan including 49 hospitalized patients on maintenance hemodialysis and 52 hospitalized patients without kidney failure (as controls) with confirmed COVID-19 disease. In patients on MH, the most common symptoms were fatigue and anorexia, fever and cough were less common. Contrastingly, fever, fatigue, and dry cough were the dominant symptoms in the controls. That said, early symptoms of COVID-19 can be easily confused with symptoms of uremia. ${ }^{2}$

As for mortality, Quintaliani et al., ${ }^{3}$ reported a fatality rate of $32.8 \%$ in patients under renal replacement therapy, as compared to $13.3 \%$ observed in the Italian population as of April $23^{\text {rd }}$. With regard to the situation in Germany, in a study in five dialysis outpatient centers (COVID Dialysis Working Group) they reported a fatal course in $26.8 \%$ of the patients. ${ }^{4}$ This course occurred mainly in male patients with cardiorenal syndrome type 2 in an overall hemodialysis population of 755 patients, among them 56 patients with COVID-19 infection.

In addition to the risk of becoming infected in everyday life, a risk of infection in dialysis centers can also be postulated for patients under $\mathrm{MH}$, potentially from other patients and staff. There remains a risk even when implementing hygienic measures such as FFP masks, separatable areas and regular smears, as these are not necessarily positive immediately after infection. ${ }^{5}$ As a complementary diagnostic option, antibody tests are now available as an indicator of prior COVID-19. We were therefore interested in the question of whether this kind of testing among the personnel of dialysis centers could provide information possibly enhancing patient safety. For comparison purposes, we carried out the tests among the staff of two dialysis centers (doctors, nurses, service staff) in Thuringia.

The incidence of COVID-19 infections is low in this federal state. This applies to the region around Saalfeld (population approximately 27.000), where the testing was carried out in one center. There are, however, regional differences. The region around Greiz (population approximately 23.000), where the testing was carried out in another dialysis center, was identified in early May 2020 as an area with a high prevalence of COVID-19 infections. On May $10^{\text {th }}, 2020$, according to the RKI dashboard that shows the number reported COVID-19 cases in Germany by region and state, there were $>5$ and $\leq 25$ cases per 100.000 inhabitants in the first region, in the second region $>50$ and $\leq 100$ cases occurred. $^{7}$

Both centers have separate areas for the patients and the hygiene standards are similar (JE is a hygiene consultant in both centers). In Greiz, the COVID-19 patients were exclusively dialyzed in the separated area after the diagnosis had been established by weekly
Volume 8 Issue 5 - 2020

\author{
Igor Alexander Harsch,' Armin Freiherr v \\ Saß, ${ }^{2}$ Olaf Richter, ${ }^{3}$ Jörg Epstude ${ }^{4}$ \\ 'Department of Internal Medicine II,Thuringia Clinic "Georgius \\ Agricola", Germany \\ ${ }^{2}$ Nephrological Group Practice and Dialysis Center Gera-Greiz- \\ Eisenberg, Friedhofstraße I5a, Germany \\ ${ }^{3}$ Nephrological Group Practice and Dialysis Center, Rainweg 68, \\ Germany \\ ${ }^{4}$ Department of Hospital Hygiene, Thuringia Clinic "Georgius \\ Agricola", Germany
}

\section{Correspondence: Igor Alexander Harsch, Thuringia Clinic Saalfeld “Georgius Agricola”, Rainweg 68, D-073 I 8 Saalfeld/Saale, $\mathrm{Tel}+49[0] 367 \mathrm{I} / 54$ I 569; Fax +49[0]367I/54I403,}

Email iharsch@thuerigen-kliniken.de

Received: September 05, 2020 | Published: September 14, 2020

PCR. After obtaining informed consent, and with approval by the Ethics Committee of the State Medical Association of Thuringia, the serum samples of the staff were taken in July 2020 and the antibody testing for IgA and IgG was done by an ELISA (EUROIMMUN"T, a PerkinElmer, Inc. company). Characteristics of the centers and results are as follows (Table 1):

Table I Characteristics of the centers and results of the antibody testing. *Infection identified by swab with molecular testing

\begin{tabular}{lll}
\hline Location of center & Saalfeld & Greiz \\
\hline Patients under MH & 90 & 100 \\
Staff members of centers tested (n) & 25 & 24 \\
$\begin{array}{l}\text { Mean age +SD } \\
\text { Antibodies (IgA and IgG) significantly } \\
\text { elevated (>2) }\end{array}$ & 0 & $45.2+8.3$ \\
$\begin{array}{l}\text { Patients with COVID-I9 Infection* } \\
\text { Plo. }\end{array}$ & 0 & $\mathrm{I}$ \\
\hline
\end{tabular}

A prior COVID-19 infection was only detectable in one person. However, the infection had also been clinically apparent and immediately led to the usual protection and isolation measures. The low infection rate in the staff is an expression of the generally low infection rate in the federal state, but also of the good implementation of the measures to protect against infection (also in everyday life) by the center staff. Antibody determinations can confirm this, but new findings or measures that could lead to an improvement in patient safety cannot be derived from them, at least in areas with a low prevalence of COVID-19 infection.

\section{Declarations}

There was no financial support. 


\section{Acknowledgments}

We are grateful to the people who provided their blood samples to support scientific research.

\section{Conflicts of interest}

There are no conflicts of interest.

\section{References}

1. Wu J, Li J, Zhu G, et al. Clinical Features of Maintenance Hemodialysis Patients with 2019 Novel Coronavirus-Infected Pneumonia in Wuhan, China. Clin J Am Soc Nephrol. 2020;CJN.04160320.

2. Gedney N. Long-Term Hemodialysis during the COVID-19 Pandemic. Clin J Am Soc Nephrol. 2020;CJN.09100620.
3. Quintaliani G, Reboldi G, Di Napoli A, et al. Exposure to novel corona virus in patients on renal replacement therapy during the exponential phase of COVID-19 pandemic: survey of the Italian Society of Nephrology. Journal of Nephrology. 2020;33:725-736.

4. Seidel M, Hölzer B, Appel H, et al. Impact of renal disease and comorbidities on mortality in hemodialysis patients with COVID-19: a multicenter experience from Germany. Journal of Nephrology. 2020;1-4.

5. Wang Z, Wang J, He J. Active and Effective Measures for the Care of Patients with Cancer during the COVID-19 Spread in China. JAMA Oncol. 2020.

6. Robert Koch Institut COVID-19: Fallzahlen in Deutschland und weltweit. 2020.

7. Robert Koch Institute COVID-19: COVID-19-Dashboard. 